\title{
Sonolência excessiva diurna com ênfase em estudantes de medicina: um reexame da literatura
}

\section{Excessive daytime sleepiness with emphasis on medical students: a literature review}

\author{
Cleber Queiroz Leite \\ Instituição: Centro Universitário São Lucas (UNISL), Porto Velho-RO. Universidade Iguaçu (UNIG), \\ Nova Iguaçu-RJ.
}

\section{Brian França dos Santos}

Instituição: Centro Universitário São Lucas (UNISL), Porto Velho-RO. Universidade Iguaçu (UNIG), Nova Iguaçu-RJ.

\section{RESUMO}

A sonolência excessiva diurna é comum entre os estudantes de medicinas, onde esse marco pode acarretar em consequências graves. Assim, enfatiza-se a necessidade de criar medidas que visem equilibrar a rotina dos estudantes de medicina, primando a sua qualidade de vida.

Palavras-chave: Sonolência excessiva diurna, Estudantes de medicina, Distúrbios do sono por sonolência excessiva.

\begin{abstract}
Excessive daytime sleepiness is common among medical students, where this milestone can have serious consequences. Thus, it emphasizes the need to create measures aimed at balancing the routine of medical students, prioritizing their quality of life.
\end{abstract}

Keywords: Excessive daytime sleepiness, Medical students, Excessive sleepiness sleep disorders.

\section{INTRODUÇÃO}

A sonolência excessiva diurna (SED) é caracterizada como uma tendência aumentada ao sono com uma compulsão subjetiva para dormir (SILVA RRP, et al., 2020) Portanto, ela é definida como a incapacidade de permanecer acordado e alerta ao longo do dia, com episódios de longa duração que causam períodos involuntários de sonolência ou sono (GARCIA JAN, et al., 2019). Logo, ela é considerada um tipo de dissonia, sendo caracterizada com distúrbios para iniciar ou manter o sono normal, ou seja, apresenta alterações na quantidade, qualidade ou regulação no ritmo do sono do indivíduo (PISFIL LSC, et al., 2020).

Nesse sentido, vários estudos apontam que os estudantes de medicina costumam ser uma população em risco de sofrer de sonolência excessiva diurna (OLIVEIRA MCS, et al., 2020), devido ao rigoroso número de horas de estudos, quantidade expressiva de carga horária por disciplinas e atividades de ensino prático e turnos noturnos em hospitais, que podem levar à privação de sono ou déficit de sono (GARCIA JAN, et al., 2019), et., 2019). E por esses motivos que é importante compreender a relação e os impactos que a sonolência excessiva diurna pode causar à saúde desses acadêmicos (SILVA RRP, et al., 2020). 


\section{OBJETIVO}

Revisar sobre a sonolência excessiva diurna, através da literatura científica dos últimos cinco anos, de forma integrativa, esclarecendo a relação e os impactos que a sonolência excessiva diurna pode causar à saúde dos acadêmicos de medicina.

\section{MÉTODO}

Trata-se de uma revisão da literatura, baseada nas bases da Biblioteca Virtual em Saúde (BVS), por meio dos descritores "Sonolência excessiva diurna", "Estudantes de Medicina", "Distúrbios do sono por sonolência excessiva”, obtendo-se como resultado 45 publicações. Nos critérios de inclusão estão artigos publicados nos últimos cinco anos, correspondendo a partir do ano de 2016 e regidos nas línguas portuguesa e espanhola. Nos critérios de exclusão estão artigos que não cumpriam com os parâmetros de inclusão e os que não abordavam o tema proposto, sendo assim foram selecionados 6 artigos de maior relevância que serviram de pesquisa para a elaboração deste trabalho.

\section{REVISÃO BIBLIOGRÁFICA}

O sono é um fenômeno fisiológico vital, essencial e necessário para a manutenção da saúde e da homeostase corporal (PURIM KSM, et al., 2016), e nele acaba envolvendo múltiplos mecanismos fisiológicos, bem como comportamentais presentes em diversos sistemas e regiões do sistema nervoso central (GARCIA JAN, et al., 2019). Portanto, o dormir de forma adequada tem funções essenciais na solidificação de vários processos como o da memória e o da restauração da energia corporal (VEGA ESS, et al., 2020).

Quando há falta de higiene do sono, as atividades diárias são totalmente prejudicadas por sensações de fadiga mental, falta de concentração e irritabilidade (GARCIA JAN, et al., 2019). Na qual isso acaba impactando diretamente o desempenho durante o dia, pois reduz a capacidade de reação e reflexos para reagir a situações críticas e imprevistas (SILVA RRP, et al., 2020). Dessa forma, horas de sono perdidas são acumulativas e, diante desse déficit, a única solução que o cérebro encontra para recuperá-la é quando o indivíduo dormi (VEGA ESS, et al., 2020).

Nessa perspectiva, uma das principais consequências geradas pelos distúrbios do sono é o esgotamento mental, uma vez que tanto a exaustão emocional e a sonolência excessiva diurna acabam influenciando no conjunto biopsicossocial (PISFIL LSC, et al., 2020). Dessa forma, a literatura científica atual mostra que a sonolência excessiva diurna em estudantes de medicina está relacionada a diversos distúrbios neurológicos e psiquiátricos, podendo gerar prejuízos seja na qualidade de vida, bem como impactando no seu desempenho acadêmico (SILVA RRP, et al., 2020). 


\section{DISCUSSÃO}

Diversas literaturas destacam que estudantes de medicina são populações vulneráveis a sonolência excessiva diurna, devido apresentarem uma extensa carga horária curricular, além das circunstâncias sociais e pessoais (GARCIA JAN, et al., 2019). Aliada a isso uma grande diversidade de conduta pode influenciar negativamente o sono como horários de sono irregulares, consumo de café, energéticos, álcool e etc. (OLIVEIRA MCS, et al., 2020).

Segundo estudos de PURIM KSM, et al., 2016, os estudantes de medicina apresentam sonolência excessiva diurna (SED) parecido à dos médicos em residências, justificando que a pressão emocional frente a essa população se inicia já no período acadêmico. Em contrapartida nos estudos de VEGA ESS, et al., 2020, foi indicado que a (SED) é significativamente maior no sexo feminino quando comparado com o masculino.

\section{CONSIDERAÇÕES FINAIS}

A dedicação significativa dos estudantes de medicina pode acabar acarretando problemas como esgotamento mental e sonolência excessiva diurna. Além dos estudantes apresentarem uma carga horária ampla, os mesmo acabam buscando complementar a sua graduação realizando atividades extracurriculares, como ligas acadêmicas, monitorias em disciplinas, iniciações científicas entre outras, tudo em prol de uma melhor qualificação profissional. Assim, enfatiza-se a necessidade de criar medidas que visem equilibrar a rotina dos estudantes de medicina, primando a sua qualidade de vida. 


\section{REFERÊNCIAS}

1. GARCIA JAN, et al. Factores asociados con somnolencia diurna excesiva en estudiantes de Medicina de una institución de educación superior de Bucaramanga. Revista Colombiana de Psiquiatría, 2019, 48(4), 222-231.

2. OLIVEIRA MCS, et al. Qualidade do sono e sonolência excessiva diurna em acadêmicos de medicina. Revista Eletrônica Acervo Saúde, 2020, 12(10), e4011-e4011.

3. PISFIL LSC, et al. La somnolencia diurna y su relación con la inteligencia emocional en estudiantes universitarios. Lima, Perú. Revista MediSur, 2020, 18(2), 195-202.

4. PURIM KSM, et al. Privação do sono e sonolência excessiva em médicos residentes e estudantes de medicina. Revista do Colégio Brasileiro de Cirurgiões, 2016, 43(6), 438-444.

5. SILVA RRP, et al. Qualidade do sono e sonolência excessiva entre estudantes de medicina. Revista de Medicina, 2020, 99(4), 350-356.

6. VEGA ESS, et al. Sonolência diurna e qualidade de vida em estudantes de Medicina. Revista Interdisciplinar de Saúde e Educação, 2020, 1(1), 24-34. 